\title{
Article
}

\section{Development of a Filtered Containment Venting System for Nuclear Power Plants}

\author{
Shinichi KAWAMURA ${ }^{1, *}$, Takeo KIMURA ${ }^{1}$, Shuichi OMORI ${ }^{2}$ \\ and Tadashi NARABAYASHI ${ }^{3}$ \\ ${ }^{1}$ Nuclear Asset Management Department, Tokyo Electric Power Company \\ 1-1-3 Uchisaiwai-cho, Chiyoda-ku, Tokyo 100-8560, Japan \\ ${ }^{2}$ Research and Development Center, Tokyo Electric Power Company, \\ 4-1 Egasaki-cho, Tsurumi-ku, Yokohama 230-8510, Japan \\ ${ }^{3}$ Division of Energy and Environmental Systems, Graduate School of Engineering, \\ Hokkaido University, Kita-13, Nishi-8, Kita-ku, Sapporo 060-8628, Japan
}

\begin{abstract}
A filtered containment venting system was developed for nuclear power plants. In the Fukushima Dai-ichi Nuclear Accident, widespread land contamination was caused by cesium-137. This system was developed to filter aerosol particles and reduce the amount of radioactive particle release, while protecting the primary containment vessel from over pressure by venting gas from the vessel. Performance tests were conducted under various vent gas flow rate conditions to ascertain decontamination factors for aerosol particles with various diameters. It was observed through the tests that aerodynamic diameter was a good index for characterizing various aerosol particles for the filtered containment venting system. Test results showed that the decontamination factors were well over 1,000 for aerosol particles with aerodynamic diameters larger than $0.4 \mu \mathrm{m}$. For aerosol particles with aerodynamic diameters larger than $0.2 \mu \mathrm{m}$, the decontamination factors significantly increased with the diameter. This suggested that inertial deposition was the governing mechanism for filtering aerosols in this system. The decontamination factor of the water scrubber section of the filter increased with the increase in Stokes number.
\end{abstract}

KEYWORDS: filtered containment vent system, nuclear power plant, accident, primary containment vessel, cesium, aerosol, particle size, decontamination factor, performance, experiment

\section{Introduction}

In 2011, the Great East Japan Earthquake and the subsequent tsunami led to an accident at the Fukushima Daiichi Nuclear Power Plant. Although the reactor scram successfully inserted all the control rods into the reactor cores of operating plants during the tremors, cooling after the scram failed due to damage caused by the tsunami, which resulted in the meltdown of the core. In addition, a part of the reactor containment vessel was damaged and large amounts of

\footnotetext{
* Corresponding author, E-mail: shinichi.kawamura@tepco.co.jp

DOI : 10.15669 /fukushimainsights.Vol.4.439

(C) 2021 Atomic Energy Society of Japan. All rights reserved.

Originally published in Transactions of the Atomic Energy Society of Japan (ISSN 1347-2879), Vol. 15, No. 1, p.12-20

(2016) in Japanese. (Japanese version accepted: July 31, 2015)
} 
radioactive materials were released into the environment. Based on the lessons learned from this accident, enhanced measures that will prevent core damage have been sought. These enhancements include the protection of safety functions against not only earthquakes and tsunamis, but also a wider range of external events, the addition of alternative high-pressure injection systems for reactors, alternative operation systems for reactor depressurization, alternative low-pressure injection systems, alternative cooling systems as a contingency measure for potential accidents, the establishment of response operation procedures, and the implementation of training programs.

In addition, considering the possibility of a severe accident in which the reactor core is damaged despite these measures, a filtered containment venting system for nuclear power plants was developed. As a result of the accident that occurred at the Fukushima Daiichi Nuclear Power Plant, the long-term and widespread soil contamination, which was mainly due to radioactive cesium, has had a significant impact on the lives of residents and industrial activities, including agriculture.

A filtered containment venting system can protect a containment vessel against overpressure failure in the event of a severe accident and significantly reduce emissions of radioactive materials. Radioactive cesium is emitted mainly in particulate form. According to Soffer et al. ${ }^{1)}$ and Beahm et al. ${ }^{2}, 95 \%$ of the radioactive iodine emitted from a reactor primary system in the event of an accident is in particulate form such as cesium iodide, and the remaining $5 \%$ is in gaseous form.

When the $\mathrm{pH}$ of the water in the containment vessel is kept alkaline, a large portion of the gaseous iodine is elemental iodine, and organic iodine accounts for only $0.15 \%$ or less ${ }^{1,2}$. Since materials other than organic iodine can be absorbed into alkaline water, they can be absorbed into the scrubber water of the filtering device described in this article. This article describes the development of a filtering device for use in the filtered containment venting system and, in particular, the details of the particulate material removal process and outcomes, based on experimental results.

Experiments were conducted on filtering devices to verify their overall removal performance based on the ratio of aerosol concentration at the intake to that at the exit of the filter ${ }^{3,4}$, but detailed characteristics of the removal were not provided. However, to ensure high removal performance, it is important to understand and improve the removal performance achieved by scrubbing the aerosol-laden gas and trapping aerosolized liquid droplets containing radioactive materials and dispersed in the gaseous phase after scrubbing. Therefore, in developing this filtering device, we experimentally determined the removal performances of both scrubbing and entrained liquid droplet trapping, which finally resulted in a major improvement in the overall removal performance. We also sought to improve the removal performance significantly with innovations to the scrubbing process such as combining the scrubber nozzle and the air bubble subdividing device, water surface stabilization using the flow regulating plate located in the upper part of the scrubbing section, and removal of entrained material using metal filters.

In addition, since the aerosol removal characteristics are generally dependent on particle diameter and density, it is important to know how these factors influence the removal characteristics. This knowledge will inform procedures for selecting mitigation and vent operation methods in the event of an accident. Thus, in this article, the removal characteristics were examined in detail using particles of different sizes and densities. 


\section{Development of a Filtered Containment Venting System}

\section{Development Conditions}

Severe accidents in a light-water reactor may occur in various ways depending on the initiating event and the success or failure of components that incorporate safety functions. Moreover, to achieve cooling after a reactor scram, injection of water into damaged fuel and spraying of water into the containment vessel are needed, using permanent or portable alternative water injection equipment. However, if there is no mechanism to ultimately release the exchanged heat, inevitably the containment vessel pressure will reach its limit due to internally generated steam. At this point, venting from the containment vessel is required to enable depressurization and thermal transport to the atmosphere. In addition, since venting also discharges hydrogen from the containment vessel, it is expected to prevent explosions due to the leakage of hydrogen from the containment vessel into the reactor building, unlike what was experienced in the accident that occurred at the Fukushima Daiichi Nuclear Power Plant.

In a boiling water reactor (BWR), the process of treating the vent gas with the suppression chamber water inside the containment vessel was established as an accident management measure to reduce the level of radioactive materials to some extent before releasing the gas to the atmosphere. In a filtered containment venting system, a dedicated filtering device is added to remove particulate radioactive materials such as cesium hydroxide and cesium iodide at higher efficiency.

Thus, we established the following conditions for developing a filtered containment venting system:

- A filtered containment venting system should remain functional at the upper limits of the pressure and temperature ranges where it has been confirmed that overpressure and over temperature failure of the containment vessel will not occur even in the event of a severe accident. These limits were set as the maximum operating pressure and temperature. In the case of an advanced boiling water reactor (ABWR), the limits are $620 \mathrm{kPa}$ (gauge) and $200^{\circ} \mathrm{C}$, respectively.

- To ensure the depressurization of the containment vessel, considering the decay heat at two or three hours after a reactor scram, twice the steam flow equivalent to $1 \%$ of the rated reactor thermal output was set as the design flow rate (31.6 kg/s in the case of the ABWR).

- The decontamination factor (DF) for particulate radioactive materials of 1,000 or higher was set as the performance target.

In addition to the aforementioned conditions, we considered the following design issues from the perspective of ensuring sufficient reliability to enable operation even in the event of a severe accident:

- The necessary safety functions must not be lost due to external events that need to be considered in the design, including design basis earthquake motion and tsunami.

- Common-cause failures of safety functions must not occur between the filtered containment venting system and the design basis accident mitigation systems.

- The filtering device is made with highly corrosion-resistant materials and measures against spillover are taken to deal with unexpected leakage.

- Not only is the entire system filled with nitrogen gas on standby, but also, accumulated hydrogen is purged with nitrogen gas after venting to prevent hydrogen explosion.

- The necessary operations can be conducted safely and reliably both from the main control room and elsewhere on site.

- To reduce the influence of venting on all emergency actions, including the operation of the 
filtered containment venting system, necessary measures (such as shielding) are taken to control the exposure dose within acceptable limits.

- To maintain the water level in the filtering device within the appropriate range, a secure supply of water must be available to the device, and the discharge of water from the device into the suppression chamber in the containment vessel must also be possible even under emergency conditions (this function also involves returning the radioactive materials collected in the filtering device to the containment vessel after venting).

- The water level, $\mathrm{pH}$, inlet pressure, metal filter pressure difference, outlet radiation intensity, hydrogen concentration, and drain transfer flow rate of the filtering device must be able to be monitored during use, on standby, and after use.

- Tests or inspections must be possible to conduct, to check whether or not the necessary safety functions are being maintained.

Sodium thiosulfate and sodium hydroxide are added to the water in the filtering device to maintain an alkaline and reducing environment. Thus, the iodine ions generated from cesium iodide aerosol trapped in water remain in the water, and a chemical reduction that traps gaseous elemental iodine as $\mathrm{I}^{-}$ions in the water is also expected:

$$
4 \mathrm{I}_{2}+\mathrm{S}_{2} \mathrm{O}_{3}^{2-}+10 \mathrm{OH}^{-} \rightarrow 8 \mathrm{I}^{-}+2 \mathrm{SO}_{4}^{2-}+5 \mathrm{H}_{2} \mathrm{O}
$$

In addition, sodium thiosulfate serves as a surfactant and has the effect of decreasing the size of the bubbles in the water to increase the gas-liquid contact interface.

\section{Description of the Filtered Containment Venting System}

\section{(1) System configuration}

Figure 1 shows the system configuration of the filtered containment venting system. The gas containing radioactive materials is discharged from the gaseous phase of the suppression chamber or the dry well of the containment vessel, fed to the filtering device through a pipe, and then released at a height after it has been treated. The isolation valves of the containment vessel need to be opened at the time of venting. These valves can be operated from the main control room and elsewhere on site. To manage operator exposure, a mechanism that operates manually and remotely through the shield is provided for the on-site operation of each valve.

The gas release pipe downstream of the filtering device is equipped with a pressure release plate that serves as a barrier to fill the entire system with nitrogen gas on standby. Filling the

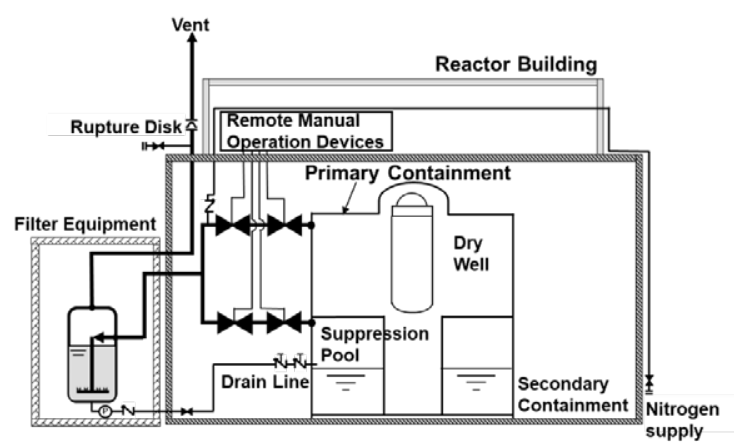

Figure 1 Basic system configuration of the filtered containment venting system 
reactor containment vessel and the inside of this system with nitrogen gas prevents hydrogen contained in the gas from burning in this system even when the steam of the vent gas condenses in the pipe at the early stage of venting. This pressure release plate is designed to operate at a pressure of $100 \mathrm{kPa}$ (gauge), which is low enough (relative to the design pressure of the containment vessel) not to interfere with the venting process.

\section{(2) Filtering device}

Figure 2 shows a schematic representation of the structure of the filtering device, which consists of the water scrubber and the metal filters. The vent gas from the containment vessel enters from the inlet nozzle in the middle to the inside and is injected into the water from 140 scrubber nozzles located in the lower portion of the device. The air bubble subdividing device installed above the nozzles enhances trapping of particulate radioactive materials by increasing the gas-liquid contact area.

The gaseous phase is in the upper portion of the device, where 128 metal filters are placed to trap radioactive fine particles that could not be removed by the water scrubber and liquid droplets. Each element has a cylindrical triple-layered structure that mainly consists of a sintered sheet of metal fibers with a diameter of $2 \mu \mathrm{m}$. This sheet has the function of removing particulates and is placed between two web layers made of metallic fibers with a diameter of $30 \mu \mathrm{m}$. The webs support the metal fiber sheet internally and externally, collect tiny liquid droplets carried by the gas that passed through the water scrubber, and return the droplets to the water scrubber through the drainage pipe in the device.

In addition, the flow regulating plate located between the water scrubber and the metal filters regulates the gas flow to the metal filter. In the event an earthquake occurs during venting, this flow regulating plate mitigates sloshing of the scrubber water.

\section{(3) Removal mechanism of the water scrubber}

In the water scrubber, the vent gas is injected into the water through nozzles. Particulate radioactive materials are trapped in the water and removed as the bubbles of the injected gas float up. The principle of the removal mechanism depends on the particle size, as described next.

First, the particles contact the gas-liquid interface as a result of inertia or gravity and become trapped in the water to be removed. This mechanism predominantly traps the larger particles, while the smaller particles, being more influenced by interaction with gas molecules, are trapped when they contact a gas-liquid interface as the result of Brownian diffusion and

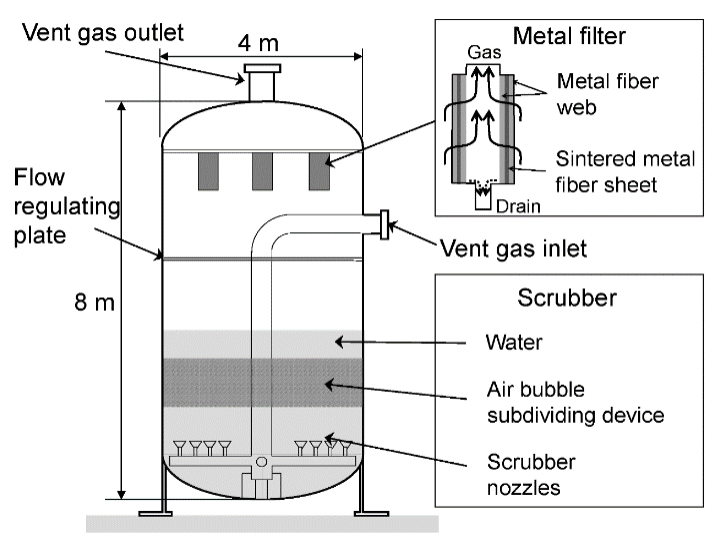

Figure 2 Schematic diagram of the filter equipment 
thermophoresis. Furthermore, when the water temperature is lower than the saturation temperature, the steam in the gas bubbles condenses and the particles become trapped as they contact the gas-liquid interface.

In addition, especially immediately after injection in the region near the scrubber nozzles, a mechanism is assumed whereby the particles are trapped in the water by their greater momentum as the lighter gas molecules in the bubble decelerate rapidly upon the injection of gas bubbles into the water.

\section{(4) Removal mechanism of the metal filter}

In the metal filter, the particulate radioactive materials are trapped and removed when the vent gas passes through the filter fibers, according to the mechanisms described next.

First, relatively large particles are blocked and trapped by the narrowness of the gaps between the metal fibers. In addition, it is assumed that the particles impact forcefully on the metal fiber surfaces and adhere to them. By these mechanisms, the larger particles are more easily trapped, while the smaller particles may be trapped, as contact with the metal filter fibers in their Brownian motion.

\section{Performance Evaluation of the Filtered Containment Venting System}

\section{Accident Scenario}

Taking the initiating event as the starting point, every accident scenario can be extracted from an event tree branched by the success or failure of the operation of a system safety function. Then, accident scenarios can be categorized into several groups. For example, in a typical accident scenario group for a BWR plant, a large break loss-of-coolant accident (LOCA), station blackout (SBO), and loss of all functions of the emergency core cooling systems (ECCS) may occur simultaneously. Assuming this scenario, we conducted experiments to confirm the performance of the filtered containment venting system using Units 6 and 7 of Kashiwazaki-Kariwa Nuclear Power Plant (ABWR plants) as an example. In terms of overpressure failure of the containment vessel, which should be preventable by the filtered containment venting system, this scenario is an extreme case in which the event progresses rapidly and the temperature and pressure of the containment vessel become high.

The event sequence of this accident scenario is as follows:

(1) A large break LOCA occurs and a large amount of coolant leaks into the containment vessel.

(2) Since an SBO and the loss of the ECCS are assumed, water cannot be injected into the reactor pressure vessel, leading to core damage.

(3) After approximately 70 minutes, an alternative low-pressure injection system powered by a gas turbine generator injects water into the reactor pressure vessel and sprays water into the containment vessel.

(4) Approximately 38 hours after the initiating event, the pressure of the containment vessel reaches the limit pressure and venting is conducted by the filtered containment venting system.

We used MAAP code for accident analysis. Figures 3 and $\mathbf{4}$ show the pressure and temperature changes in the containment vessel in this accident scenario. The charts indicate that the venting system keeps the temperature and pressure of the containment vessel at or below the limit temperature $\left(200^{\circ} \mathrm{C}\right)$ and pressure $(620 \mathrm{kPa})$, so the uncontrollable release of radioactive 


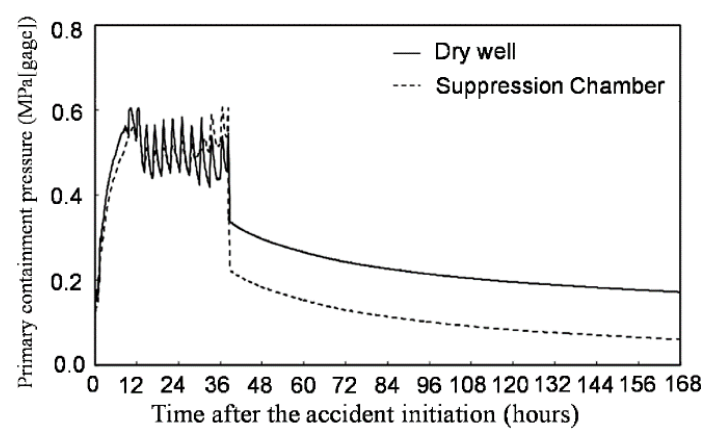

Figure 3 Primary containment pressure of an ABWR plant in a severe accident caused by a combination of LOCA, SBO, and all ECCS functional failures

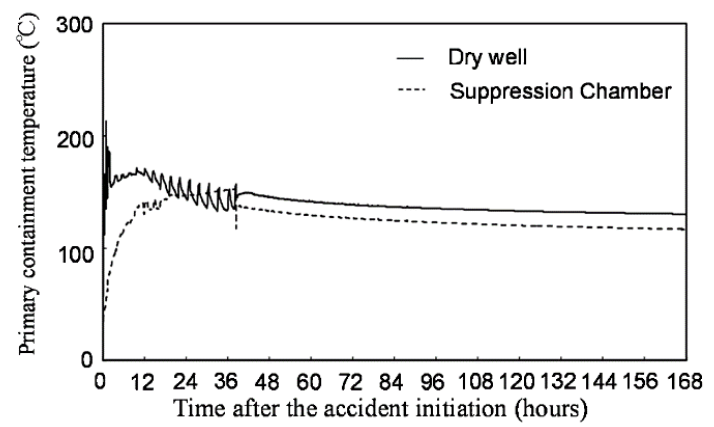

Figure 4 Primary containment temperature of an ABWR plant in a severe accident caused by a combination of LOCA, SBO, and all ECCS functional failures

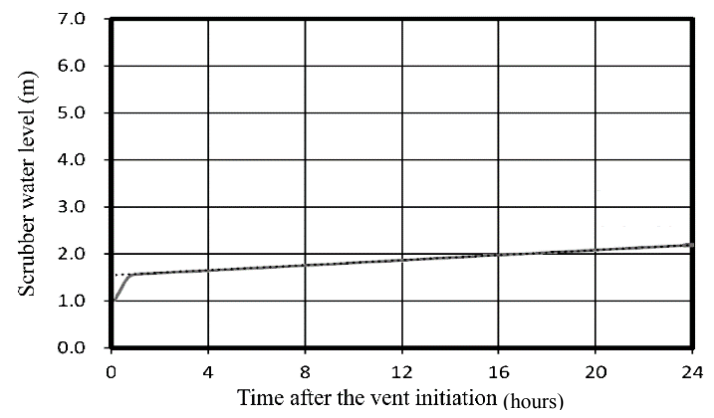

Figure 5 Predicted trend of the scrubber water level during containment venting

materials into the environment due to failure of the containment vessel can be prevented.

Continued gas venting raised the water level of the water scrubber. Figure $\mathbf{5}$ shows the predicted change of the water level. The total amount of steam condensate in the vent pipe flowing into the filtering device and that in the filtering device is larger than the amount of evaporation caused by the radioactive materials trapped in the water scrubber. Therefore, the water level continues to rise during venting. Although the installed position of the metal filters corresponds to a water level of $5 \mathrm{~m}$, it is impossible to maintain the performance of the system when the water level reaches the metal filters, and an operation to lower the water level is required. Thus, 
we incorporated a draining system into the filtering device to discharge the scrubber water into the containment vessel suppression chamber when the water level reaches $2.5 \mathrm{~m}$, considering the spout that could occur due to aeration of the vent gas, and to supply water and sodium thiosulfate and sodium hydroxide solutions to the scrubber.

\section{Performance Test Facility and Test Conditions for the Filtering Device}

\section{(1) Test facility}

Figure 6 shows the configuration of the test facility used for the performance test. By feeding air mixed with simulation particles from the aerosol generator through a test chamber designed to resemble the actual filtering device, we measured the number density and diameter of the particles at the front and back of the test chamber to calculate DF. For the measurement, we used a light-scattering type aerosol spectrometer (Welas digital $2000 \mathrm{H}$ manufactured by Palas $\mathrm{GmbH}$ ) and a scanning type mobility particle sizer (Model 3936 manufactured by TSI Inc.).

In the test chamber, we placed a scrubber nozzle and metal filter identical to those used in the actual device, and we also filled the air bubble subdividing device with the same element as that used in the actual device, up to the same height as in the actual device. The diameter of the test chamber was $0.35 \mathrm{~m}$ and its average flow passage cross sectional area was $1 / 140$ of that of the actual device, thus achieving the same operating conditions per scrubber nozzle as that of the actual device. However, since the gaseous phase between the water scrubber and the metal filter does not affect the particle removal mechanism, this section was shortened to reduce the height to $4 \mathrm{~m}$, as shown in Figure 6.

\section{(2) Test gas}

In this test, air at ordinary temperature and pressure was used as the test gas. In contrast, the gas that is vented in a severe accident mainly consists of steam at $120^{-} 170^{\circ} \mathrm{C}$. As described next, the test we conducted using air at ordinary temperature is considered conservative in

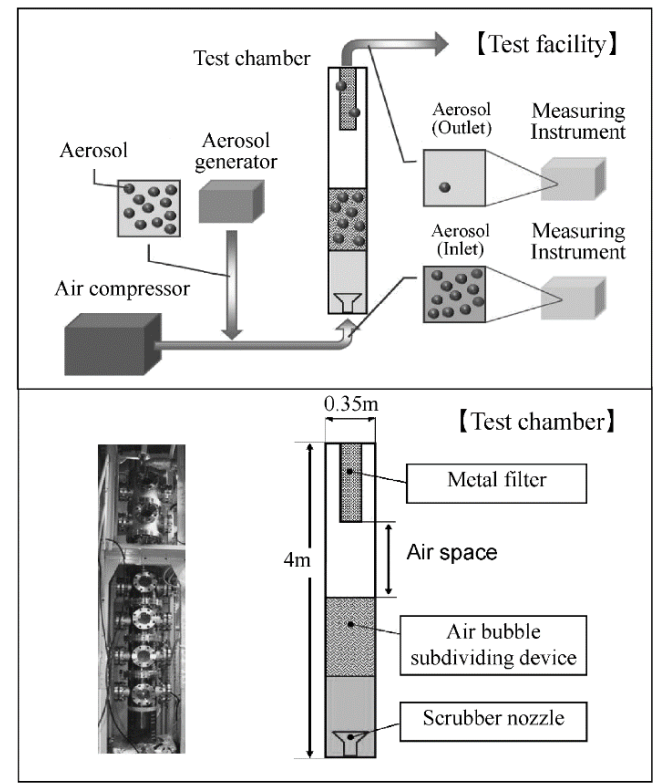

Figure 6 Performance test facility for the filter equipment 
terms of the particle trapping mechanism.

First, trapping by inertial collision produces a larger effect as the Stokes number $(\mathrm{St})^{5)}$ increases; however, there are no significant differences in St between the test gas and the vent gas when the particle diameter is $0.4 \mu \mathrm{m}$ or less. On the other hand, at larger particle diameters, St in the case of air at ordinary temperature and pressure becomes smaller than that under the steam conditions that could develop in a severe accident. Therefore, the test conducted using air at ordinary temperature and pressure is conservative in terms of the trapping effect based on inertial collision. The Stokes number is calculated by the following equations:

$$
\begin{aligned}
& \mathrm{St}=\mathrm{D}_{\mathrm{p}}^{2}\left(\rho_{\mathrm{p}}+\rho / 2\right) \mathrm{C}_{\mathrm{c}} \mathrm{u}_{0} /\left(9 \eta \mathrm{D}_{\mathrm{f}}\right) \\
& \mathrm{C}_{\mathrm{c}}=1+\mathrm{K}_{\mathrm{n}}\left(1.257+0.4 \exp \left(-1.1 / \mathrm{K}_{\mathrm{n}}\right)\right) \\
& \mathrm{K}_{\mathrm{n}}=2 \lambda_{\mathrm{g}} / \mathrm{D}_{\mathrm{p}} \\
& \lambda_{\mathrm{g}}=\eta /\left(0.499 \mathrm{P}(8 \mathrm{M} / \pi \mathrm{RT})^{1 / 2}\right)
\end{aligned}
$$

where, $\mathrm{D}_{\mathrm{p}}$ is the particle diameter, $\rho_{\mathrm{p}}$ is the particle density, $\rho$ is the gas density, $\mathrm{C}_{\mathrm{c}}$ is a slip correction coefficient, $\mathrm{u}_{0}$ is the gas flow velocity, $\eta$ is the gas viscosity, $\mathrm{D}_{\mathrm{f}}$ is a characteristic diameter in the fluid, $\mathrm{T}$ is the gas temperature, $\mathrm{P}$ is the gas molecular weight, and $\mathrm{R}$ is the gas constant.

Trapping by gravitational sedimentation is considered to produce a larger effect as the gravitational sedimentation velocity $\left(\mathrm{v}_{\mathrm{t}}\right)^{5)}$ increases. However, there is no significant difference in gravitational sedimentation velocity between the test gas and the vent gas when the particle diameter is $0.4 \mu \mathrm{m}$ or less. On the other hand, at larger particle diameters, $\mathrm{v}_{\mathrm{t}}$ in the case of air at ordinary temperature and pressure becomes smaller than that under the steam conditions that could develop in a severe accident. Therefore, the test conducted using air at ordinary temperature and pressure is conservative in terms of the trapping effect based on gravitational sedimentation. The gravitational sedimentation velocity is calculated by the following equation:

$$
\mathrm{v}_{\mathrm{t}}=\mathrm{C}_{\mathrm{c}} \mathrm{D}_{\mathrm{p}}^{2}\left(\rho_{\mathrm{p}}-\rho\right) \mathrm{g} / 18 \eta
$$

where, $\mathrm{g}$ is gravitational acceleration, and the other variables are as defined previously.

Although trapping by diffusional deposition is considered to produce a larger effect as the Brownian diffusion coefficient (D) ${ }^{5}$ increases, the Brownian diffusion coefficient in the case of air at ordinary temperature and pressure is smaller than that under the steam conditions that could develop in a severe accident. Therefore, the test conducted using air at ordinary temperature and pressure is conservative in terms of the trapping effect based on diffusional deposition. The Brownian diffusion coefficient is calculated by the following equation:

$$
\mathrm{D}=\mathrm{C}_{\mathrm{c}} \mathrm{kT} / 3 \pi \eta \mathrm{D}_{\mathrm{p}}
$$

where, $\mathrm{k}$ is the Boltzmann constant, and the other variables are as defined previously.

In addition to the aforementioned mechanisms, trapping by steam condensation and trapping by thermophoresis are also assumed under steam conditions, but the test conditions are conservative because these effects are not expected in the test using air at ordinary temperature and pressure.

\section{(3) Simulation particles}

The transition of particulate radioactive materials in the water scrubber from gas (bubbles) to water and the adhesion of particulate radioactive materials in the metal filter from gas to 
metal fiber surfaces are based on the physical movement of the particles and are not entirely dependent on their chemical properties. Therefore, for the simulation particles in our test, we used titanium oxide with a density relatively close to those of cesium hydroxide and cesium iodide, which are typical particulate radioactive materials observed during venting, and ferric oxide. The densities of $\mathrm{TiO}_{2}, \mathrm{CsOH}, \mathrm{CsI}$, and $\mathrm{Fe}_{2} \mathrm{O}_{3}$ are $4.23 \mathrm{~g} / \mathrm{cm}^{3}, 3.68 \mathrm{~g} / \mathrm{cm}^{3}, 4.51 \mathrm{~g} / \mathrm{cm}^{3}$, and $5.24 \mathrm{~g} / \mathrm{cm}^{3}$, respectively. In addition, as standard particles for the aerosol test, we used polystyrene standard particles (PSL), which are commonly employed. The density of PLS is $1.05 \mathrm{~g} / \mathrm{cm}^{3}$.

\section{(4) Test condition for scrubber water}

The water level in the test chamber was set at $1 \mathrm{~m}$ above the top edge of the scrubber nozzle, which corresponds to the water level in the actual device on standby. As shown in Figure 5, the scrubber water level rises during venting. And, as the scrubber water level increases, the vent gas goes through the water for a longer period of time, and the particles are more easily trapped. Therefore, this test condition, corresponding to the lowest water level in the actual device, is conservative.

The water in the test chamber was at ordinary temperature. In the actual device, the thermal energy of the vent gas and the decay heat of the radioactive materials raise the temperature of the scrubber water to the saturation temperature according to the pressure in the filter device. On the other hand, while the water temperature is lower than the gas temperature, as the temperature difference between the water and the gas increases, the particles are more easily trapped due to thermophoresis and the reduction of bubbles after steam condensation. However, this test condition is conservative because air at ordinary temperature and pressure was used as the test gas.

Since this test is intended to determine the particulate matter removal performance, sodium thiosulfate and sodium hydroxide, which are additives for removing gaseous inorganic iodine, were not added.

\section{(5) Gas flow rate test condition}

The gas flow rate was set to cover the conditions of use of the actual device. Figure 7 shows the change in the vent gas flow rate in the scenario that assumes an accident at an ABWR plant. The highest flow rate occurs immediately after venting at the limit pressure of the containment vessel. Subsequently, the flow rate decreases according to the amount of steam generated in the containment vessel. Therefore, we simulated three conditions in the performance test and set the test flow rate to $1 / 140$ of the corresponding volumetric flow rates in the actual device, as follows:

- Maximum flow rate condition: $33,000 \mathrm{~m}^{3} / \mathrm{h}$, which is the volumetric flow rate immediately

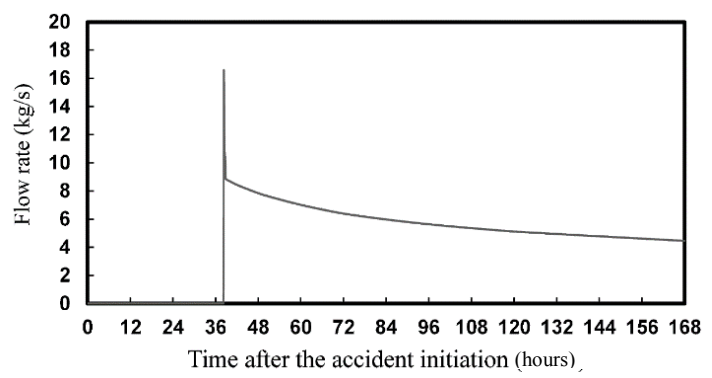

Figure 7 Predicted trend of vent gas flow rate 
after venting at twice the design pressure of the containment vessel (620 $\mathrm{kPa}$ (gage)).

- Medium flow rate condition: $27,000 \mathrm{~m}^{3} / \mathrm{h}$, which is the volumetric flow rate immediately after venting at the design pressure of the containment vessel $(310 \mathrm{kPa}$ (gage)).

- Minimum flow rate condition: $13,500 \mathrm{~m}^{3} / \mathrm{h}$, which is the volumetric flow rate set as a condition lower than the flow rate observed seven days (168 hours) after the occurrence of the accident.

\section{Results of the Removal Performance Test Conducted on the Filtering Device}

\section{(1) Particulate material removal performance}

Figures 8-10 show the results of measuring the DFs of the particulate materials.

These figures also show the distribution of particle sizes flowing into the filtered containment venting system from the containment vessel suppression chamber in the accident scenario described previously (a large break LOCA at an ABWR plant, loss of all ECCS functions, and SBO), which was obtained by analysis using MAAP code.

When the DF exceeds 10,000, particles may not be detected at the exit.

In such a case, the integrated values of the number of particles detected at the entrance of the filter during the measurement period were plotted as the reference value of DF. Although this value corresponds to the DF of the case assuming one particle is detected at the exit, no particles

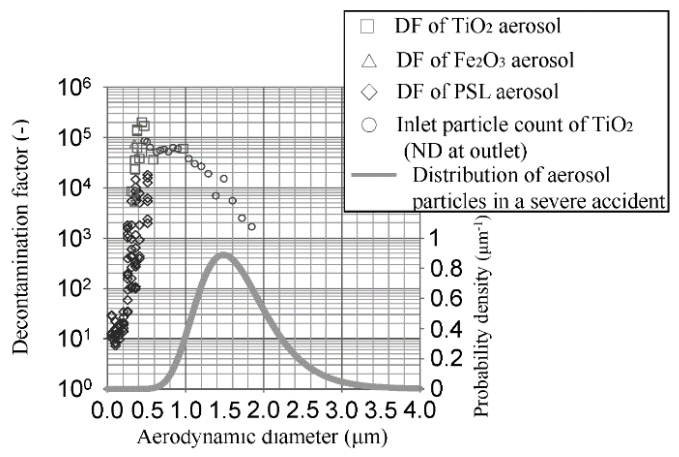

Figure 8 Measured decontamination factor at the maximum vent flow condition (a simulated venting flow rate of $33,000 \mathrm{~m}^{3} / \mathrm{h}$ at twice the maximum containment design pressure)

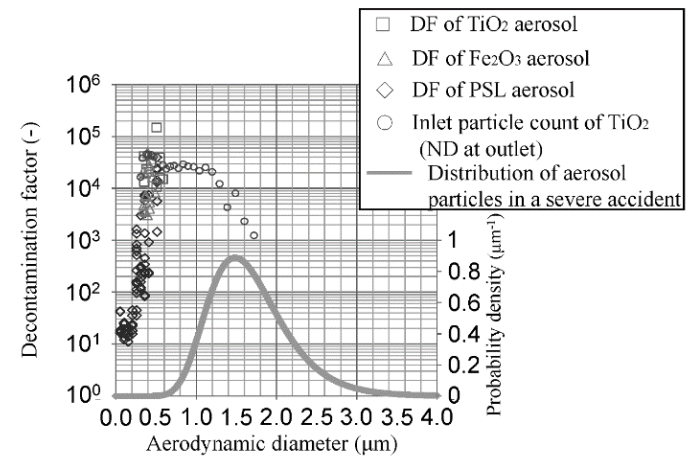

Figure 9 Measured decontamination factor at the medium vent flow condition (a simulated venting flow rate of $27,000 \mathrm{~m}^{3} / \mathrm{h}$ at the maximum containment design pressure) 


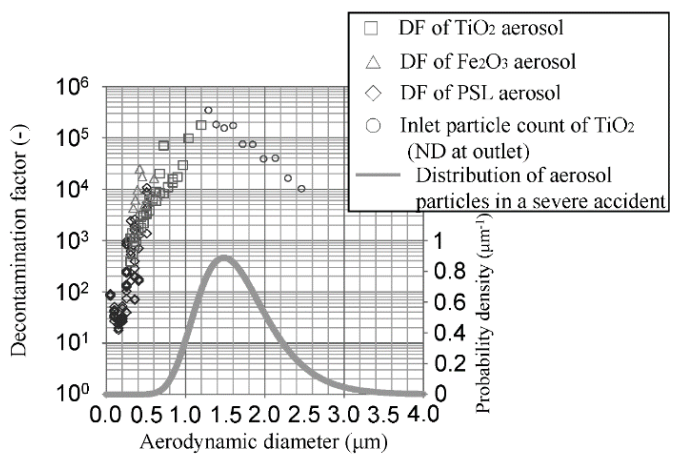

Figure 10 Measured decontamination factor at the minimum vent flow condition (a simulated venting flow rate of $13,500 \mathrm{~m}^{3} / \mathrm{h}$ )

were detected in the actual measurement. Therefore, it can be estimated that the DF was higher than this reference value. This reference DF value was used to determine whether a measured DF was equal to or higher than the target value $(1,000)$. The reference DF value decreased as the particle diameter increased because the number density of test particles decreased with the particle diameter and the integrated value of the particle number at the entrance became smaller. Therefore, it did not show a reduction tendency for DF.

In Figures 8-10, the DFs were plotted against the aerodynamic diameter of test particles with different densities on the abscissa. The aerodynamic diameter is the diameter of a hypothetical sphere with a density of $1 \mathrm{~g} / \mathrm{cm}^{3}$, which achieves the same terminal velocity as the particle to be studied in viscous fluids similar to air. The aerodynamic diameter is represented by the following equation ${ }^{6}$ :

$$
\mathrm{D}_{\mathrm{ae}}=\left(6 \rho_{\mathrm{p}} \alpha_{\mathrm{e}} / \pi \mathrm{K}_{\mathrm{R}}\right)^{1 / 2} \mathrm{D}_{\mathrm{p}}
$$

where, $D_{a e}$ is the aerodynamic diameter, $\alpha_{\mathrm{e}}$ is the volume shape factor of the particles, $K_{R}$ is the resistance shape factor of particles, and the other variables are as defined previously.

Figures 8-10 show identical DF distributions as a result of the particles organizing according to their aerodynamic diameter regardless of the test particles used. From this result, we found that organizing according to the aerodynamic diameter is effective in determining the performance of the filter.

The measured DFs increased monotonically when the aerodynamic diameter was equal to or larger than approximately $0.2 \mu \mathrm{m}$. Since the metal filter blocks particles that are larger than a certain size, and inertial collision is a dominant removal mechanism for smaller particles, we inferred that the effect of an inertial collision increased with the aerodynamic diameter. On the other hand, for the scrubber, the mechanisms whereby larger particles yield a higher removal effect include inertial collision and gravitational sedimentation, and it is possible that the effect of either one of these mechanisms increased.

Therefore, for the purpose of investigating the trapping mechanism in the scrubber, we conducted a test in which only the DFs based on the scrubber were measured, with the metal filters removed. We used $\mathrm{TiO}_{2}$ as the particles for the test. Figure 11 shows the measured DFs, which are organized according to the Stokes number. As this figure shows, the DFs increase with the Stokes number. In addition, even though the flow rates are different, the DFs shows somewhat similar tendencies when organized according to the Stokes number. Thus, we inferred that the 


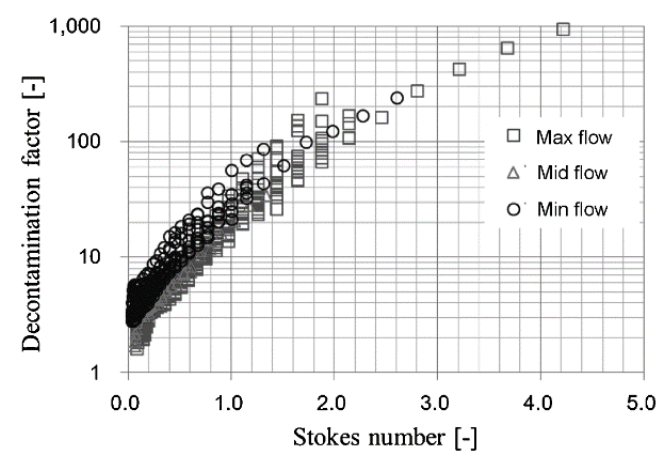

Figure 11 Relationship between measured decontamination factor of the scrubber and Stokes number ("Max flow," "Mid flow," and "Min flow" represent simulated venting flow rates of $33,000 \mathrm{~m}^{3} / \mathrm{h}, 27,000 \mathrm{~m}^{3} / \mathrm{h}$, and $13,500 \mathrm{~m}^{3} / \mathrm{h}$ respectively)

influence of inertial collision is significant in causing the increase in DF due to the scrubber.

These insights provide useful knowledge for further improving the performance of the scrubber in the future. Although lengthening the retention time in the scrubber water is required for gravitational sedimentation to have a significant influence on performance, an improvement that focuses on the Stokes number, such as increasing the ejection flow rate from the scrubber nozzle, is considered effective because inertial collision has a more significant influence.

As a particle trapping mechanism, using the scrubber under accident conditions, the effect of trapping the particles at the gas-liquid interface due to steam condensation is expected at the early stage of venting, but this effect will diminish because the scrubber water temperature increases with time. However, from our test results, we found that the required removal performance can be achieved by the trapping mechanism based on inertial collision, even if the scrubber water temperature increases as a result of continuing the venting when an accident occurs.

As mentioned earlier, the distribution of particle sizes in Figures 8-10 was calculated by MAAP code with the assumption that the vent gas was discharged from the containment vessel suppression chamber. This distribution was referred to because the DFs tend to increase when the aerodynamic diameter is equal to or greater than $0.2 \mu \mathrm{m}$ and this case gives a relatively smaller size distribution. The aerodynamic diameters in this case were distributed between $0.5 \mu \mathrm{m}$ and $4 \mu \mathrm{m}$, with the peak between $1 \mu \mathrm{m}$ and $2 \mu \mathrm{m}$. When venting from the dry well but not from the suppression chamber in the same accident scenario, the aerodynamic diameters of the particles flowing into the filtered containment venting system ranged from $0.7 \mu \mathrm{m}$ to $10 \mu \mathrm{m}$, with the peak between $3 \mu \mathrm{m}$ and $4 \mu \mathrm{m}$. The reason why the particle size distribution shifted to the larger particle diameters is that there was no scrubbing effect by the suppression chamber. In addition, when we considered an alternative accident scenario that involved injection failure at high and low pressures, we obtained an almost identical particle size distribution as when venting was conducted from the suppression chamber in the scenario of a large break LOCA at an ABWR plant, with loss of all ECCS functions, and SBO. Regarding the size distribution of the aerosol particles in the containment vessel at the time of the accident, we found several examples based on analyses or experiments in past studies ${ }^{7-9)}$ that reported distributions with median diameters of several micrometers and geometric standard deviations of several micrometers. The results of our analyses are consistent with the outcomes of these previous studies.

Considering the particle size distributions and the DFs, we found that the DFs exceeded the development target of 1,000 in the range of our test, including the range of aerodynamic diameters where no particle was detected at the exit of the filter. In addition, for aerodynamic 
diameters that exceed the range of our test, it was inferred that the DFs exceeded that obtained for the diameter at the upper limit of the test range because inertial collision increases with the aerodynamic diameter. Furthermore, for larger particle sizes, the DFs are expected to be equal to or larger than 1,000 because of the additional effect of gravitational sedimentation in the scrubber and blocking by the metal filter.

\section{(2) Liquid droplet removal performance of the metal filter}

In this test, water-insoluble solid particles were used as simulation particles. However, the main particles observed in a severe accident are cesium iodide and cesium hydroxide, which are both water soluble. The fact that the simulation particles are water-insoluble is deemed conservative for the water scrubber performance evaluation and does not affect the performance of the metal filter. Therefore, this approach is also considered to be conservative in the evaluation of the particle removal performance of the filtering device.

However, in the event of a severe accident, it is conceivable that radioactive materials dissolve in the scrubber water, and that some of them are suspended by entrainment in liquid droplets downstream of the water scrubber. The metal filter also serves as a demister that traps these liquid droplets and returns them to the water scrubber to prevent them from scattering farther downstream. We confirmed this performance in our test.

Although the basic configuration of the test device was the same as that used to measure the particulate material removal performance (as shown in Figure 6), we used clean air rather than aerosols in this test. In addition to the two particle measurement points shown in Figure 6, we

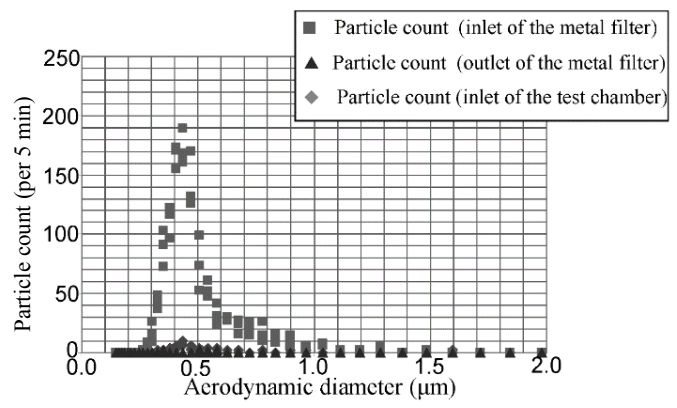

Figure 12 Comparison of the amount of entrained droplets between the inlet and the outlet of the metal filter (a simulated venting flow rate of $33,000 \mathrm{~m}^{3} / \mathrm{h}$ at twice the maximum containment design pressure)

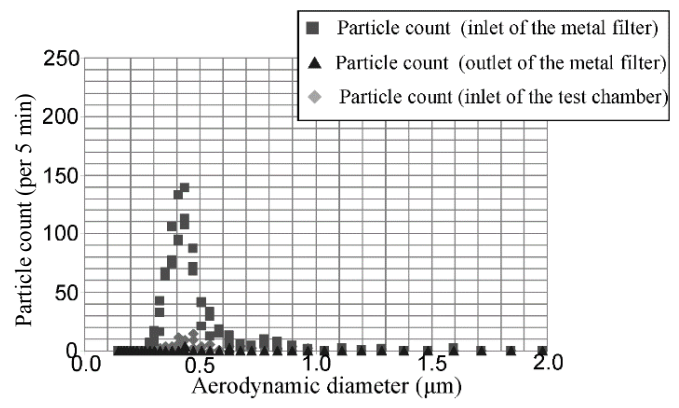

Figure 13 Comparison of the amount of entrained droplets between the inlet and the outlet of the metal filter (a simulated venting flow rate of $13,500 \mathrm{~m}^{3} / \mathrm{h}$ ) 
added a third point near the entrance of the metal filters for liquid droplet measurement. Thus, we confirmed the liquid droplet removal performance of the metal filter by comparing the numbers and sizes of liquid droplets at the entrance and exit of the metal filters.

Figures 12 and 13 show the test results under the maximum and minimum flow rate conditions. Under both conditions, we confirmed that almost no liquid droplets were detected at the exit of the metal filter, and that the filter is effective in preventing the dissolved radioactive materials from being released into the environment by entrainment.

\section{Conclusions}

Based on the lessons learned from the accident that occurred at the Fukushima Daiichi Nuclear Power Plant, enhanced protection of safety functions against external events and enhanced measures to prevent core damage have been sought. Considering a severe accident where a reactor core is damaged, we developed a filtered containment venting system. This system is deemed capable of protecting a containment vessel from overpressure failure in the event of a severe accident and of reducing emissions of particulate radioactive materials into the environment to $1 / 1,000$ or less. It was radioactive cesium that caused long-term and widespread environmental impacts from the accident that occurred at the Fukushima Daiichi Nuclear Power Plant, and cesium is emitted mainly as a particulate material. In addition, radioactive iodine is emitted mostly as particulate cesium iodide. Therefore, this system is expected to mitigate the environmental impact significantly in the event of a severe accident.

To ensure high removal performance in the filtered venting, the performance of the scrubbing section and the removal of liquid droplet entrainment containing the radioactive materials in the gaseous phase after scrubbing are important. Therefore, in developing the filtered containment venting system, we sought ways to improve the removal performance significantly by adding innovations such as combination of the scrubber nozzle with the air bubble subdividing device, water surface stabilization using the flow regulating plate located in the upper part of the scrubbing section, and removal of entrainment using metal filters.

In addition, since the aerosol removal characteristics are generally dependent on particle diameter and density, it is important to understand these characteristics in considering the procedures for selecting the mitigation and vent operation methods in the event of an accident. In this study, we confirmed the characteristics of DFs that are dependent on the particle diameter. In addition, in considering the characteristics of DFs based on particles with different densities, we confirmed that the aerodynamic diameter is an effective index. Since the characteristics of particulate materials, such as particle size distribution, vary with the stage of progress of an accident and the existence of a containment vessel spray, the insights gained from this study can contribute to plant management decisions for selecting mitigation and vent operation methods in the event of an accident and determining which method maximizes the release inhibition effect.

Furthermore, within the range of particle size distributions assumed present in a containment vessel after a severe accident, we concluded that inertial collision is a significant trapping mechanism in a filtering device, among several trapping mechanisms. In particular, for the scrubber, the DF is correlated with the particle diameters and the venting flow rates by the Stokes number. Moreover, we found that the removal performance of the scrubber was enhanced by inertial collision even when steam condensation no longer occurred due to the increase in water temperature caused by continuous venting. 


\section{References}

1) L. Soffer, S. Burson, C. Ferrell, R. Lee, J. Ridgely, Accident Source Terms for Light-water Nuclear Power Plants, U.S. Nuclear Regulatory Commission, NUREG-1465 (1995).

2) E. Beahm, C. Weber, T. Kress, G. Parker, Iodine Chemical Forms in LWR Severe Accidents, U.S. Nuclear Regulatory Commission, NUREG/CR-5732 (1992).

3) I. Wall, M. Merilo, Containment Filtration Systems Tests, Electric Power Research Institute, EPRI TR100346 (1992).

4) N. Losch, S. Buhlmann, C. Hutterer, C. Stiepani, F. Totsuka, T. Tsukahara, K. Hosomi, “AREVA's filtered containment venting system (FCVS)," Proc. 19th Power and energy technology symposium, Fukui, Japan, Jun. 26-27, 2014 (2014).

5) K. Okuyama, H. Masuda, S. Morooka, Biryuushi Kougaku, Oomu-sha, Tokyo, ISBN4-272-12900-4 (1992). [in Japanese]

6) K. Takahashi, Earozorugaku no Kiso, Morikita-syuppan, Tokyo, ISBN4-627-67251-9 (2003). [in Japanese]

7) H. Allelein, A. Auvinen, J. Ball, S. Guntay, L. Herranz, A. Hidaka, A. Jones, M. Kissane, D. Powers, G. Weber, State-of-the-art Report on Nuclear Aerosols, NEA/CSNI/R (2009) 5, Nuclear Energy Agency/ Committee on the safety of nuclear installations (2009).

8) D. Powers, S. Burson, A Simplified Model of Aerosol Removal by Containment Sprays, NUREG/CR5966, U.S. Nuclear Regulatory Commission (1993).

9) D. Powers, A Simplified Model of Decontamination by BWR Steam Suppression Pool, NUREG/CR6153, U.S. Nuclear Regulatory Commission (1997). 